\title{
Polar Vantage and Oura physical activity and sleep trackers: A validation study
}

\author{
André Henriksen ${ }^{1, *}$, Frode Svartdal ${ }^{2}$, Sameline Grimsgaard $^{1}$, Gunnar Hartvigsen ${ }^{3}$, Laila Hopstock ${ }^{1}$ \\ ${ }^{1}$ UiT The Arctic University of Norway, Department of Community Medicine \\ ${ }^{2}$ UiT The Arctic University of Norway, Department of Psychology \\ ${ }^{3}$ UiT The Arctic University of Norway, Department of Computer Science \\ *Corresponding author: andre.henriksen@uit.no, Hansine Hansens veg 18, 9037 Troms $\varnothing$
}

\begin{abstract}
Objectives: Consumer-based accelerometers (activity trackers) are increasingly used in research. The aim of this study was to test the validity of the Polar Vantage watch and Oura ring activity trackers for measuring physical activity (PA), total energy expenditure (EE), resting heart rate (RHR), and sleep duration, when worn by adults in free-living.

Design, setting, and participants: Twenty-one participants wore four activity trackers; Polar, Oura, ActiGraph, and Actiheart, and completed a sleep diary for up to seven days. We assessed criterion validity of Polar and Oura when measuring PA, TEE, RHR (Oura), and sleep duration. We analysed repeated measures correlation, Bland-Altman plots, and mean absolute percentage error (MAPE).

Results: Polar and Oura were both strongly correlated $(\mathrm{p}<0.001)$ with ActiGraph for steps (Polar $r$ 0.75, 95\% CI 0.54-0.92. Oura $r$ 0.77, 95\% CI 0.62-0.87), moderate-to-vigorous PA (MVPA) (Polar $r$ 0.76, 95\% CI 0.62-0.88. Oura $r 0.70,95 \%$ CI 0.49-0.82), and TEE (Polar $r 0.69,95 \%$ CI 0.48-0.88. Oura $r 0.70,95 \%$ CI $0.51-0.83)$ and strongly or very strongly correlated $(\mathrm{p}<0.001)$ with the sleep diary for sleep duration (Polar $r 0.74,95 \%$ CI $0.56-0.88$. Oura $r 0.82,95 \%$ CI $0.68-0.91$ ). Oura was very strongly correlated $(\mathrm{p}<0.001)$ with Actiheart for RHR ( $r 0.9,95 \%$ CI 0.85-0.96). MAPE was high for all variables except Oura sleep duration (10\%), and RHR (3\%) where Oura under-reported on average one beat per minute.

Conclusions: Oura can potentially be used as an alternative to Actiheart to measure RHR. For sleep duration, Polar and Oura can potentially be used as a replacement for a manual sleep diary. Neither Polar nor Oura can replace ActiGraph for measuring steps, MVPA, and TEE, but may be used as an additional source of PA in some settings.
\end{abstract}

\section{Article Summary}

\section{Strengths and limitations of this study}

- Major strength is the analysis of multiple days of recordings instead of one mean measure per participant

- Wide ranges of participant age, height, weight, body mass index, and gender balance

- Main limitation is the use of criteria validated using gold standards, but are not themselves considered gold standard in all settings

Keywords: Epidemiology, Public health, Medical informatics 
medRxiv preprint doi: https://doi.org/10.1101/2020.04.07.20055756; this version posted April 11, 2020. The copyright holder for this preprint (which was not certified by peer review) is the author/funder, who has granted medRxiv a license to display the preprint in perpetuity. It is made available under a CC-BY-NC 4.0 International license .

\section{Introduction}

Physical activity (PA) can be objectively measured using accelerometers; small, lightweight, and noninvasive wearable device that measures acceleration in one or more axis. Acceleration is converted into various estimates for PA, energy expenditure (EE), sleep and heart rate (HR) [1, 2], depending on device. A wide range of accelerometers exist, aimed at both research [3] and the consumer marked [4].

Consumer-based activity trackers are increasingly used in research as it has potential to increase activity participation [5]. Consumer-based activity trackers are often cheaper, less intrusive, and with increased battery and storage capacity, compared to research-based accelerometers. They can also decrease participant burden compared with self-report instruments such as PA- and sleep diaries. Sleep diaries [6] are less resource demanding compared with polysomnography (PSG), but compliance can be challenging [7]. Using consumer-based activity trackers to measure sleep duration can therefore be a potential replacement for sleep diaries.

The accuracy of newer consumer-based devices is mostly unknown, and validity studies are needed. Criterion validity of consumer-based activity trackers can be studied by comparison against researchbased accelerometers (e.g. ActiGraph) that, in turn, have been validated against gold standard methods. The Polar Vantage watch and the Oura ring are two new consumer-based activity trackers that potentially can replace research-based accelerometers or self-report tools.

The aim of this study on free-living adults was therefore to test the criterion validity of PA and EE, measured by Polar Vantage and Oura, compared to ActiGraph, as well as resting heart rate (RHR) measured by the Oura compared to Actiheart electrocardiography. In addition, we aimed to compare sleep duration between measures from a sleep diary and the Polar Vantage and Oura.

\section{Methods}

\section{Instruments}

The Polar Vantage activity tracker (Polar Electro oy, Finland) was released in 2018 and is equipped with a $50 \mathrm{~Hz}$ (i.e. measurements per second) triaxial accelerometer for PA tracking. It weighs 45-66 grams, has one week of battery life, and comes in multiple strap- and metal casing colours. Polar Vantage is a multisport watch to be worn on the wrist. A previous lab-based validation study of Polar Vantage found that accuracy of EE was moderately or higher, depending on activity [8]. No validation study on PA or sleep has been conducted on the Polar Vantage to date, and no study on this activity tracker has been done in free-living populations.

The Oura activity- and sleep ring (Oura oy, Finland) was released in 2018 and equips a $50 \mathrm{~Hz}$ triaxial accelerometer for PA tracking and a two infrared LED (light-emitting diode) photoplethysmograph for optical pulse measurements. It comes in sizes US 6 to US 13, weighs 4-6 grams, has six days of battery life, and comes in different shapes and colours. Oura is a smart ring to be worn on the finger and focuses on sleep and wellbeing by combining PA and HR parameters. De Zambotti et al. [9] conclude that the Oura shows "promising results" for sleep detection, when compared with PSG. However, there are no previous validation studies testing the validity of PA, EE, and RHR for the Oura.

The ActiGraph wGT3X-BT (ActiGraph, Pensacola, FL, USA) is a triaxial accelerometer. Sample rate can be set to 30-100 Hz. It weighs 19 grams and has up to 25 days of battery life. It is extensively used to estimate activity in free-living research, as it provides reasonable estimates for PA intensity [10], steps [11], and EE [12]. 
medRxiv preprint doi: https://doi.org/10.1101/2020.04.07.20055756; this version posted April 11, 2020. The copyright holder for this preprint (which was not certified by peer review) is the author/funder, who has granted medRxiv a license to display the preprint in perpetuity.

It is made available under a CC-BY-NC 4.0 International license.

The Actiheart 4 (CamNtech Ltd, Cambridge, UK) records HR using a 1-lead electro-cardiogram (ECG), with $128 \mathrm{~Hz}$ sampling rate. It weighs less than 10 grams and is attached to the chest using two standard ECG electrodes. Actiheart is valid and reliable for HR detection [13].

The sleep diary contained a sub-set of questions from the Consensus Sleep Diary [14] relevant for sleep duration measured as time in bed; specifically question 1) "what time did you get into bed", and question 7) "what time did you get out of bed for the day".

\section{Participants and procedure}

We used convenience sampling to recruit 21 healthy volunteers aged 18 years and above.

We initialized the devices with self-reported information on height, weight, age, sex, and dominant hand. Participants wore the Polar Vantage and Oura on the non-dominant hand. The ActiGraph was setup for $100 \mathrm{~Hz}$ recording and placed on the right hip, attached with an elastic band. The Actiheart was placed at the level of the fifth intercostal space at the sternum (medial part) and to the left (lateral part), attached with two 3M Red Dot 2238 electrodes (3M, St Paul, MN, USA). Participants wore all four devices simultaneously as well as completing the sleep diary, for up to seven days. Data were collected May-June 2019. Figure 1 show device placements.

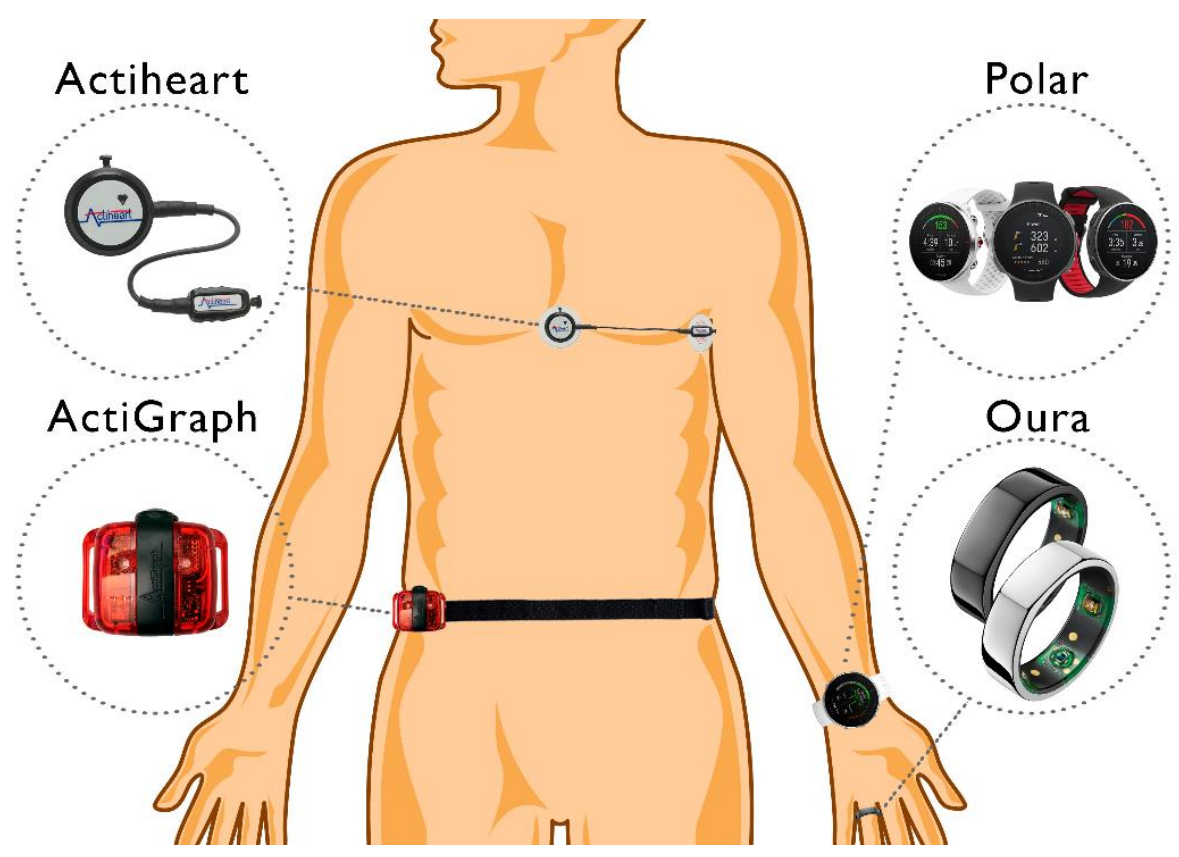

Figure 1. Illustration of instrument placement for Actiheart, Polar, ActiGraph, and Oura

An overview of instrument details and software used for setup, data download, and variable generation, is given in Table 1.

Table 1. Overview of instrument supplier, model, firmware version, and software version used to setup, download, and generate output variables.

\begin{tabular}{lllll}
\hline Instrument & Actiheart & Polar Vantage & ActiGraph & Oura \\
\hline Supplier & CamNTech & Polar Electro & ActiGraph & Oura \\
Model & 4 & V/M & wGT3X-BT & 2P \\
Firmware version & H90.65 & 3.2 .10 & 1.9 .2 & 1.91 .1 \\
\hline
\end{tabular}


medRxiv preprint doi: https://doi.org/10.1101/2020.04.07.20055756; this version posted April 11, 2020. The copyright holder for this preprint (which was not certified by peer review) is the author/funder, who has granted medRxiv a license to display the preprint in perpetuity. It is made available under a CC-BY-NC 4.0 International license .

\begin{tabular}{lllll}
\hline Software for instrument setup, data & Actiheart & Polar Flow [15] & ActiLife & Oura app \\
download, and variable generation & 5.1 .10 & & 6.13 .3 & {$[16]$}
\end{tabular}

\section{Variable generation}

We used Polar Flow (Polar Electro oy, Finland) to download daily Polar Vantage variables for steps, MVPA, TEE, and sleep duration (sleep time). The Oura application was used to download daily Oura variables for steps, MVPA, TEE, sleep duration (total sleep), and RHR. We used ActiLife (ActiGraph, Pensacola, FL, USA) to download ActiGraph accelerometer data and generate variables. We used triaxial activity (i.e. vector magnitude (VM)) counts to generate PA and EE variables, in addition to steps, which was reported directly. We calculated minutes of MVPA using cut-points defined by Sasaki et al. [10], i.e. $>2690$ VM. Activity energy expenditure (AEE) was calculated using "Freedson VM3 combination $2011+$ Williams work-energy equation" (Sasaki et al [10]), and converted to TEE using the Schofield equation [17] for resting energy expenditure and removing $10 \%$ to account for diet-induced thermogenesis. The Actiheart software was used to download sleeping HR (i.e. RHR) from the Actiheart (CamNtech Ltd, Cambridge, UK).

We only included valid days in the analysis, defined as at least 10 hours of wear time [18]. Wear time for the ActiGraph was analysed using the ActiLife default settings for the Troiano [19] wear time algorithm. Wear time algorithms for Polar Vantage and Oura are unknown.

\section{Statistics}

The ActiGraph was used as criterion measure for steps, MVPA, and TEE. The Actiheart was used as criterion measure for RHR. The sleep diary (time in bed) was used as criterion measure for sleep duration (Polar: sleep time, Oura: total sleep). Normality was tested using the Shapiro-Wilkins test and bootstrapping was used on all variables. Correlations were calculated using repeated measures correlation (RMC) [20, 21, 22], with correlation cut-offs suggested by Evans [23]. Mean absolute percentage error (MAPE) was calculated using a cut-off of $10 \%$ to indicate low error for studies conducted in free-living $[24,25]$. Bland-Altman plots for multiple measurements was created to determine agreement between each instruments and the criterion [26].

\section{Results}

\section{Participant characteristics}

Summary statistics for the participants' age, sex, height, weight, and body mass index, are given in Table 2.

Table 2. Participant characteristics for age, sex, height, weight, and body mass index $(N=21)$.

\begin{tabular}{lrr}
\hline Variable & Value & Range \\
\hline Age, years & $33(14)$ & $22-71$ \\
Males, $\%$ & $57(12)$ & N/A \\
Height, cm & $176(9)$ & $160-190$ \\
Weight, $\mathrm{kg}$ & $79(13)$ & $57-103$ \\
Body mass index, $\mathrm{kg} / \mathrm{m}^{2}$ & $26(4)$ & $18-35$ \\
\hline Values are means (standard deviations) and range, or percentages (numbers). N/A: Not applicable
\end{tabular}


medRxiv preprint doi: https://doi.org/10.1101/2020.04.07.20055756; this version posted April 11, 2020. The copyright holder for this preprint (which was not certified by peer review) is the author/funder, who has granted medRxiv a license to display the preprint in perpetuity.

It is made available under a CC-BY-NC 4.0 International license.

Each participant had 2-6 valid days of PA recording, totalling 57 (Polar Vantage) and 68 (Oura) valid person-days of simultaneous ActiGraph and activity tracker usage. Participants manually recorded 0-5 days of sleep, totalling 48 (Polar Vantage) and 44 (Oura) person-days of sleep diary and activity tracker recordings. There were 39 person-days of Oura and Actiheart RHR recordings.

\section{Correlation and agreement}

Table 3 and Table 4 presents valid person-days, correlations, MAPEs, mean difference with limits of agreement for steps, MVPA, TEE, sleep duration, and RHR (Oura), for the Polar Vantage and the Oura, respectively.

Table 3. Repeated measures correlation (RMC), mean absolute percentage errors (MAPE), and mean difference for each Polar Vantage variable.

\begin{tabular}{|l|r|r|r|r|}
\hline Measure & Person-days (n) & RMC (95\% CI)* & MAPE & $\begin{array}{r}\text { Mean difference } \\
\text { (lower LoA, upper LoA) }\end{array}$ \\
\hline Polar Vantage & & & & \\
\hline Steps & 57 & $0.75(0.54-0.92)$ & $72 \%$ & $4091(-2693,10876)$ \\
\hline MVPA & 57 & $0.76(0.62-0.88)$ & $143 \%$ & $59(-148,266)$ \\
\hline Total energy expenditure & 57 & $0.69(0.48-0.88)$ & $19 \%$ & $430(-267,1127)$ \\
\hline Sleep duration & 48 & $0.74(0.56-0.88)$ & $13 \%$ & $-30(-183,123)$ \\
\hline
\end{tabular}

MVPA: moderate-to-vigorous physical activity. LoA: limits of agreement. *All RMC p-values $<0.001$.

Table 4. Repeated measures correlation (RMC), mean absolute percentage errors (MAPE), and mean difference for each Oura variable.

\begin{tabular}{|l|r|r|r|r|}
\hline Oura & Person-days (n) & RMC (95\% CI)* & MAPE & $\begin{array}{r}\text { Mean difference } \\
\text { (lower LoA, upper LoA) }\end{array}$ \\
\hline Steps & 68 & $0.77(0.62-0.87)$ & $69 \%$ & $3779(-3361,10919)$ \\
\hline MVPA & 68 & $0.70(0.49-0.82)$ & $49 \%$ & $-18(-96,61)$ \\
\hline Total energy expenditure & 68 & $0.70(0.51-0.83)$ & $13 \%$ & $148(-624,920)$ \\
\hline Sleep duration & 44 & $0.82(0.68-0.91)$ & $10 \%$ & $6(-152,164)$ \\
\hline Resting heart rate & 39 & $0.90(0.85-0.96)$ & $3 \%$ & $-1(-4,1)$ \\
\hline
\end{tabular}

MVPA: moderate-to-vigorous physical activity. LoA: limits of agreement. *All RMC p-values $<0.001$.

Numbers are also illustrated in Figure 2 with RMC scatterplots and Bland-Altman plots for both activity trackers. Each participant is represented with a different colour. In the scatterplots, a separate fit-line is shown for each participant. 
medRxiv preprint doi: https://doi.org/10.1101/2020.04.07.20055756; this version posted April 11, 2020. The copyright holder for this preprint (which was not certified by peer review) is the author/funder, who has granted medRxiv a license to display the preprint in perpetuity.

It is made available under a CC-BY-NC 4.0 International license .
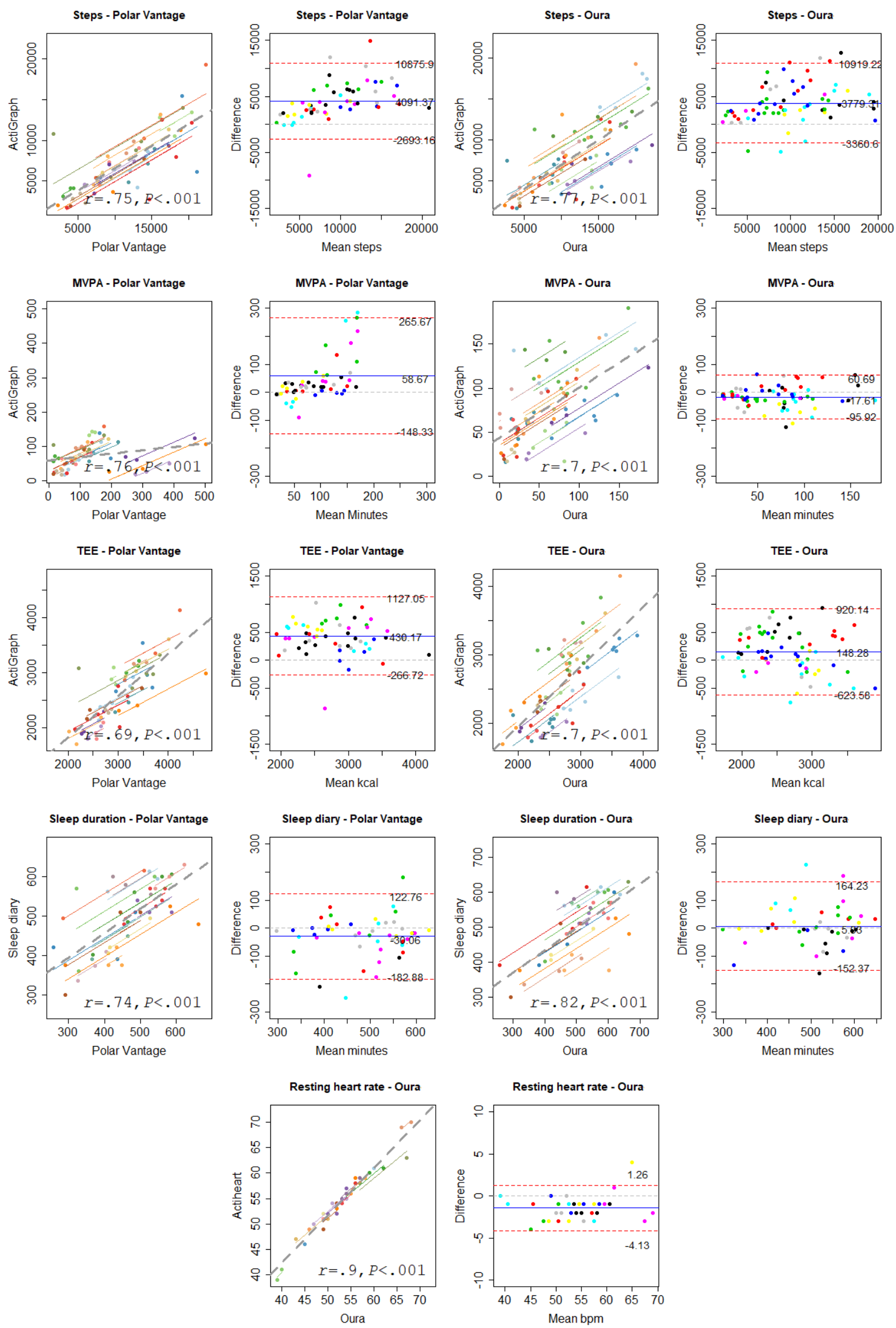

Figure 2. Polar and Oura scatterplots and Bland-Altman plots for all variables. 
medRxiv preprint doi: https://doi.org/10.1101/2020.04.07.20055756; this version posted April 11, 2020. The copyright holder for this preprint (which was not certified by peer review) is the author/funder, who has granted medRxiv a license to display the preprint in perpetuity. It is made available under a CC-BY-NC 4.0 International license .

Step counting was strongly correlated between the criterion and both the Polar Vantage and the Oura. Bland-Altman plots showed that both the Polar Vantage and the Oura over-reported steps, and MAPE were high for both activity trackers.

MVPA was strongly correlated between the criterion and both activity trackers. The Polar Vantage overreported MVPA, while the Oura under-reported MVPA. For the Polar Vantage, over-reporting was higher for higher values of MVPA. The limits of agreement range in the Bland-Altman plots was also wider for the Polar Vantage. Both MAPEs were high, but the Oura had less error compared to the Polar Vantage.

TEE was strongly correlated between the criterion and both activity trackers. Both activity trackers overreported TEE, but the Polar Vantage over-reported at a higher rate. Both MAPEs were higher than the $10 \%$ cut-off for acceptable error, but TEE had less error compared to steps and MVPA.

Sleep duration was strongly correlated between the criterion and the Polar Vantage, with a mean underreporting of 30 minutes by the Polar Vantage. The Oura was very strongly correlated with the criterion, but over-reported sleep by on average six minutes. Both activity trackers had a borderline acceptable MAPE.

$R H R$ was very strongly correlated between criterion and the Oura. MAPE was low at 3\%, and on average the Oura under-reported RHR with one beat per minute.

\section{Discussion}

Step-, MVPA-, and TEE- outputs from the activity trackers were all strongly correlated with ActiGraph. MAPE was high for these variables, with less error recorded by Oura, compared to Polar Vantage. Sleep duration was strongly to very strongly correlated between the sleep diary and both the Polar Vantage and the Oura. In addition, RHR, recorded by Oura, was very strongly correlated with Actiheart. MAPE for the sleep diary were borderline acceptable, while MAPE for RHR was acceptable.

The major strength of this study is the inclusion of multiple days of recordings for each participant instead of one mean measure per person. A further strength is the gender balance and the wide range in age, height, weight, and body mass index among participants. The major weakness of this study is the use of non-gold standard criteria for validation. However, the criteria used; the ActiGraph $[10,11,12]$ and Actiheart [13], have both been previously validated against gold standards, and were found appropriate for this study conducted in free-living.

While correlations for EE in the present study are higher than most previous Polar studies [27], it is lower compared to a lab-setting study on Polar Vantage [8] and a free-living study of Polar M430 [28]. Correlations for MVPA on previous Polar validation studies varies, but our findings are similarly high compared to findings from Polar M430 [28] and Polar V800 [29]. Similarly, strong correlations for step counting is in accordance with previous studies on Polar V800 [28, 29] and Polar M600 [30]. For Oura, we could not find any previous studies on steps, MVPA, or TEE. Even though correlations are strong, most results showed that measurement error was high, and most variables were over-reported compared to the criterion. Thus, we cannot recommend replacing existing research-based accelerometers with the activity trackers investigated in the present study. However, as an additional instrument for long term PA recording, these consumer-based activity trackers can provide additional value to studies examining changes in PA over time. TEE may be especially interesting to measure over time, since it had close to acceptable error, with $13 \%-19 \%$ mean error.

We could not find any previous validation study on sleep duration for the Polar Vantage. However, the high correlation in the present study is in accordance with findings in an earlier Polar model (Polar A370) 
medRxiv preprint doi: https://doi.org/10.1101/2020.04.07.20055756; this version posted April 11, 2020. The copyright holder for this preprint

(which was not certified by peer review) is the author/funder, who has granted medRxiv a license to display the preprint in perpetuity.

It is made available under a CC-BY-NC 4.0 International license.

[1]. Sleep duration was under-reported in both studies, which is expected since sleep onset and sleep offset are generally greater than zero minutes. The Oura over-reported sleep duration, but only by an average six minutes per night. This is in accordance with Zambotti et al. [9] who conclude that the Oura shows "promising results" for sleep detecting in their study using PSG. Both the Polar Vantage and Oura can provide reasonably close estimates for sleep duration with $10-13 \%$ average error, which is close to the acceptable cut-off. This is especially interesting for long term sleep monitoring, as keeping a manual sleep diary is prone to low compliance [7], and objective wrist-worn devices can gives more accurate results [31].

The strong correlation and low average error found for Oura RHR detection is in accordance with other studies on other fitness trackers [2]. We could not find any validation studies on Oura RHR. Compared to the Actiheart, and other similar research instruments, the Oura is a low burden device capable of collecting various HR measures over several months. This makes it an interesting instrument for future research, when long-time HR measures are of interest.

\section{Conclusions}

The Oura can be used as an alternative to Actiheart to measure RHR, unless very high accuracy is required. Similarly, Polar Vantage and Oura can potentially be used as a replacement for a manual sleep diary, for sleep duration measurements. Neither the Polar Vantage nor the Oura can replace the ActiGraph for measuring steps, MVPA, and TEE, but may be used as an additional source of PA in some settings.

\section{Funding}

This work was supported by UiT The Arctic University of Norway's thematic priority grant "Personalized medicine for public health". The publication charges for this study were granted from the publication fund at UiT The Arctic University of Norway.

\section{Competing interests}

The authors declare that they have no competing interests.

\section{Author contributors}

$\mathrm{AH}, \mathrm{FS}$, and LH conceived the study and designed the study protocol. AH collected data with support from Celina Jakobsen and Jørgen Halvorsen. AH performed data analysis, and AH, LH, SG, GH, and FS contributed to the interpretations of the results. AH drafted the initial manuscript with critical review from LH, SG, FS, and GH. All authors read and approved the final manuscript.

\section{Patient and public involvement}

Patients or the public were not involved in the design, conduct, recruitment, reporting, or dissemination of this study.

\section{Ethics Approval}

The Norwegian Regional Committees for Medical and Health Research Ethics North reviewed the study (2019/557/REK nord). Participants received written and oral instructions and gave informed consent. The study was conducted in accordance with the 1964 Declaration of Helsinki and its later amendments. 
medRxiv preprint doi: https://doi.org/10.1101/2020.04.07.20055756; this version posted April 11, 2020. The copyright holder for this preprint

(which was not certified by peer review) is the author/funder, who has granted medRxiv a license to display the preprint in perpetuity.

It is made available under a CC-BY-NC 4.0 International license .

\title{
Patient consent for publication
}

Not required.

\section{Data availability statement}

Data may be obtained from the first author upon reasonable request.

\author{
Abbreviations \\ AEE: Activity energy expenditure \\ EE: Energy expenditure \\ HR: Heart rate \\ RHR: Resting heart rate \\ MAPE: Mean absolute percentage error \\ MVPA: Moderate-to-vigorous physical activity \\ PA: Physical activity \\ PSG: Polysomnography \\ TEE: Total energy expenditure \\ RMC: Repeated measures correlation

\section{References}

1. Pesonen AK, Kuula L. The Validity of a New Consumer-Targeted Wrist Device in Sleep Measurement: An Overnight Comparison Against Polysomnography in Children and Adolescents. J Clin Sleep Med. 10.5664/jcsm.7050. 2018;14(4):585-91.

2. Nelson BW, Allen NB. Accuracy of Consumer Wearable Heart Rate Measurement During an Ecologically Valid 24-Hour Period: Intraindividual Validation Study. JMIR Mhealth Uhealth. 10.2196/10828. 2019;7(3):e10828.

3. Butte NF, Ekelund U, Westerterp KR. Assessing physical activity using wearable monitors: measures of physical activity. Med Sci Sports Exerc. 10.1249/MSS.0b013e3182399c0e. 2012;44(1 Suppl 1):S5-12.

4. Henriksen A, Haugen Mikalsen M, Woldaregay AZ, Muzny M, Hartvigsen G, Hopstock LA, et al. Using Fitness Trackers and Smartwatches to Measure Physical Activity in Research: Analysis of Consumer Wrist-Worn Wearables. J Med Internet Res. 10.2196/jmir.9157. 2018;20(3):e110.

5. Brickwood K-J, Watson G, O'Brien J, Williams AD. Consumer-Based Wearable Activity Trackers Increase Physical Activity Participation: Systematic Review and Meta-Analysis. JMIR mHealth and uHealth. 10.2196/11819. 2019;7(4):e11819-e.

6. Ibanez V, Silva J, Cauli O. A survey on sleep questionnaires and diaries. Sleep Med. 10.1016/j.sleep.2017.08.026. 2018;42:90-6.

7. Stone AA, Shiffman S, Schwartz JE, Broderick JE, Hufford MR. Patient non-compliance with paper diaries. BMJ. 10.1136/bmj.324.7347.1193. 2002;324(7347):1193-4.

8. Gilgen-Ammann R, Schweizer T, Wyss T. Accuracy of the Multisensory Wristwatch Polar Vantage's Estimation of Energy Expenditure in Various Activities: Instrument Validation Study. JMIR Mhealth Uhealth. 10.2196/14534. 2019;7(10):e14534.

9. de Zambotti M, Rosas L, Colrain IM, Baker FC. The Sleep of the Ring: Comparison of the OURA Sleep Tracker Against Polysomnography. Behav Sleep Med. 10.1080/15402002.2017.1300587. 2017:1-15.

10. Sasaki JE, John D, Freedson PS. Validation and comparison of ActiGraph activity monitors. J Sci Med Sport. 10.1016/j.jsams.2011.04.003. 2011;14(5):411-6. 
medRxiv preprint doi: https://doi.org/10.1101/2020.04.07.20055756; this version posted April 11, 2020. The copyright holder for this preprint

(which was not certified by peer review) is the author/funder, who has granted medRxiv a license to display the preprint in perpetuity.

It is made available under a CC-BY-NC 4.0 International license .

11. Lee JA, Williams SM, Brown DD, Laurson KR. Concurrent validation of the Actigraph gt3x+, Polar Active accelerometer, Omron HJ-720 and Yamax Digiwalker SW-701 pedometer step counts in lab-based and free-living settings. Journal of Sports Sciences. 10.1080/02640414.2014.981848. 2015;33(10):991-1000.

12. McMinn D, Acharya R, Rowe DA, Gray SR, Allan JL. Measuring activity energy expenditure: accuracy of the GT3X+ and actiheart monitors. International Journal of Exercise Science. 2013;6(3):217-29.

13. Brage S, Brage N, Franks PW, Ekelund U, Wareham NJ. Reliability and validity of the combined heart rate and movement sensor Actiheart. Eur J Clin Nutr. 10.1038/sj.ejcn.1602118. 2005;59(4):561-70.

14. Carney CE, Buysse DJ, Ancoli-Israel S, Edinger JD, Krystal AD, Lichstein KL, et al. The consensus sleep diary: standardizing prospective sleep self-monitoring. Sleep. 10.5665/sleep.1642. 2012;35(2):287-302.

15. Polar Electro. Polar Flow 2018 [Available from: https://flow.polar.com].

16. Oura. Oura mobile app 2019 [Available from: https://ouraring.com/introducing-the-new-ouraapp/.

17. Schofield WN. Predicting basal metabolic rate, new standards and review of previous work. Human nutrition Clinical nutrition. 1985;39 Suppl 1:5-41.

18. Troiano RP, Berrigan D, Dodd KW, Masse LC, Tilert T, McDowell M. Physical activity in the United States measured by accelerometer. Med Sci Sports Exerc.

10.1249/mss.0b013e31815a51b3. 2008;40(1):181-8.

19. Troiano RP. Large-scale applications of accelerometers: new frontiers and new questions. Med Sci Sports Exerc. 10.1097/mss.0b013e318150d42e. 2007;39(9):1501.

20. Bakdash JZ, Marusich LR. Repeated Measures Correlation. Frontiers in psychology. 10.3389/fpsyg.2017.00456. 2017;8:456-.

21. Bland JM, Altman DG. Calculating correlation coefficients with repeated observations: Part 1-Correlation within subjects. BMJ (Clinical research ed). 10.1136/bmj.310.6977.446. 1995;310(6977):446-.

22. Bland JM, Altman DG. Calculating correlation coefficients with repeated observations: Part 2-Correlation between subjects. BMJ (Clinical research ed). 10.1136/bmj.310.6980.633. 1995;310(6980):633-.

23. Evans JD. Straightforward statistics for the behavioral sciences.: Brooks/Cole Publishing; 1996.

24. Nelson MB, Kaminsky LA, Dickin DC, Montoye AH. Validity of Consumer-Based Physical Activity Monitors for Specific Activity Types. Med Sci Sports Exerc. 10.1249/MSS.0000000000000933. 2016;48(8):1619-28.

25. Roos L, Taube W, Beeler N, Wyss T. Validity of sports watches when estimating energy expenditure during running. BMC Sports Sci Med Rehabil. 10.1186/s13102-017-0089-6. 2017;9:22.

26. Bland JM, Altman DG. Agreement between methods of measurement with multiple observations per individual. J Biopharm Stat. 10.1080/10543400701329422. 2007;17(4):571-82.

27. Andre Henriksen, Jonas Johansson, Gunnar Hartvigsen, Sameline Grimsgaard, Hopstock LA. Measuring Physical Activity Using Triaxial Wrist Worn Polar Activity Trackers: A Systematic Review. International Journal of Exercise Science. 2020;13(4):438-54.

28. Henriksen A, Grimsgaard S, Horsch A, Hartvigsen G, Hopstock L. Validity of the Polar M430 Activity Monitor in Free-Living Conditions: Validation Study. JMIR Form Res. 10.2196/14438. 2019;3(3):e14438.

29. Hernandez-Vicente A, Santos-Lozano A, De Cocker K, Garatachea N. Validation study of Polar V800 accelerometer. Ann Transl Med. 10.21037/atm.2016.07.16. 2016;4(15):278.

30. Degroote L, De Bourdeaudhuij I, Verloigne M, Poppe L, Crombez G. The Accuracy of Smart Devices for Measuring Physical Activity in Daily Life: Validation Study. JMIR Mhealth Uhealth. 10.2196/10972. 2018;6(12):e10972. 
medRxiv preprint doi: https://doi.org/10.1101/2020.04.07.20055756; this version posted April 11, 2020. The copyright holder for this preprint (which was not certified by peer review) is the author/funder, who has granted medRxiv a license to display the preprint in perpetuity. It is made available under a CC-BY-NC 4.0 International license .

31. Jungquist CR, Pender JJ, Klingman KJ, Mund J. Validation of Capturing Sleep Diary Data via a Wrist-Worn Device. Sleep Disord. 10.1155/2015/758937. 2015;2015:758937-. 